\title{
Sustainable and Ecological Residence Evidence Based Design
}

\author{
Shaikh Javaria Manzoor IKIHA, IFHE, BEAM ${ }^{1, *}$, JaeSeung Park, Ph.D, NCARB, FKIA ${ }^{2}$ \\ ${ }^{1}$ Korean Institution of Healthcare Architecture(IKIHA), International Federation of Healthcare Engineering (IFHE), Biomedical \\ Engineering Associating of Malaysia (BEAM) \\ ${ }^{2}$ President IKIHA, School of Architecture, Professor Hanyang University ERICA campus Korea \\ *Corresponding Author: jaespark@hanyang.ac.kr
}

Copyright (C) 2013 Horizon Research Publishing All rights reserved.

\begin{abstract}
Perhaps on one hand Pakistan is facing severe energy crises, and on the other the planet earth is going through global warming. The only solution is low carbon planning. The purpose of this paper is to show the benefit of low energy residential designs. It is normally believed that closely controlled conditions equate with better comfort. Analysis of field surveys and adaptive comfort theories have made it clear that while closely controlled is one way of achieving comfort it is not the only way. This paper has taken into account analysis of an Eco-House designed by the author, this design considers energy efficiency in terms of passive methods; hence here is a comparative study of two types of houses. Primarily, there is a complete analysis of an existing house in UET (University of Engineering and Technology, Lahore) staff colony that adopts conventional methods of achieving comfort through energy consumption. The latter house is an Eco-House design proposal for which creative design strategies are discussed in detail.The results obtained provide us the substance to statistically show the benefits of low energy designs. The findings also highlights the importance by providing an insight details for the architects to understand the interesting elements in designing and detailing a low energy building.
\end{abstract}

Keywords ECOTECT, UET (University of Engineering and Technology Lahore), Radiation Penetration and Eco-House.

\section{Introduction}

The world today is suffering from exhaustion of energy resources. For a third world country like Pakistan the situation is even severe, where the difference between population and consumption is ever increasing. Therefore, it is compulsory to effectively utilize the limited energy resources. Thus, the architectural professionals must concentrate on designing and building such structure that consume minimum amount of energy. The highly praised solution is the constructions of ecological architecture. This paper addresses today issue, that the residential building sector uses up to $30-40 \%$ of the world's total energy consumption (I.E.A., 2008). A large portion of the energy used in buildings is used for achieving thermal comfort for the inhabitants through cooling, heating and lighting. This energy is produced by burning of fossil fuels, which result in the production of carbon dioxide. Developing countries like Pakistan is making a substantial contribution to the carbon dioxide emissions from its domestic energy usage, which is $35 \%$ of total energy consumption (ENERCON, 2006).

\section{Materials and Methods}

The discussion below reveals a complete methodology devised for this paper. It can be summarized as:

Taking the existing plan of a typical house at UET, and then calculating the energy consumption and radiation penetration, through windows and other openings.

Redesigning the house to minimize the energy consumption

Calculating and comparing the radiation penetration

Calculating the energy loads on ECOTECT software for the new design of the ecological house as well as the old house

The rapid societal changes demands from the architecture designers to shift from random creativeness to more focus and intelligent creativeness. With shorter amount of time to solve increasingly complex problems, a systematic process is necessary if ideas are to be produced on purpose (S. J. Kirk, 1988).

This paper is principally based upon the residential sector's low energy architecture design, referred as ecological architecture. The core theme of comfort is often directly related to the energy consumption i.e. if the energy utilization is high; higher will be the comfort level. This paper however, demonstrates that although high energy consumption is one way to achieve the comfort but it is not the only method. There are other alternatives available which 
are underdeveloped or less explored; some of them are discussed in this paper. Furthermore the paper also highlights other techniques of attaining comfort levels i.e. by constructing the Eco House. The research is basically a comparative analysis of two houses of a residential colony of UET Lahore. First house is already built and the data is gathered from the existing evidence collected for statistical analysis. The second house is an Eco-House; this is a purpose-built model that can be applied as a proposed design for the inventive constructions. Both the case studies are similar in terms of their number of inhabitants, income groups, life styles; the difference is in their architecture and energy consumption patterns.

Furthermore, to establish, simulate and to analyze the environmental effects of these buildings; a software namely ECOTECT is applied on the computer generated models of both the houses. The basic task of the software is to analyse the different elements for example, solar pattern, thermal loads, and acoustics and lighting effects.

Moreover, a tabular descriptive statistics is devised to analyze the sun radiation in the two principal houses. A vast investigation is conducted to gather the data of the different radiation phases on the two houses throughout the entire year. This data and the calculations are further analyzed in detail to fabricate the results and make suggestions for the future. Both the graphical and the tabular results of the research provide an innate understanding to show the significance of the ecological architecture. And the results clearly indicate the difference of energy consumption patterns in both the houses.

\section{1 Lahore Climate: Normal Composite}

The houses are situated in Pakistan's eastern city of Lahore. The city is located at the latitude of $32^{\circ}$. The seasonal difference of weather conditions in Lahore is extreme. In summer it gets very hot while in summer it turns to very cold.

As Lahore climate is normal composite because it is hot and dry in summer before monsoon season and in late August it becomes hot and humid after the annual rainy season starts; whereas in winter it is normally dry and cold. Hence Lahore, is a city with diversified climatic features carrying a lot of challenges, the aim is on one hand to protect the inhabitants from severe cold winter; while on the other hand to ensuring a cool indoor with an additional moisture during the extreme hot summer. Simultaneously good cross ventilation is an appropriate solution towards extreme humid climate during the monsoon.(Q. Shakeel 2009)

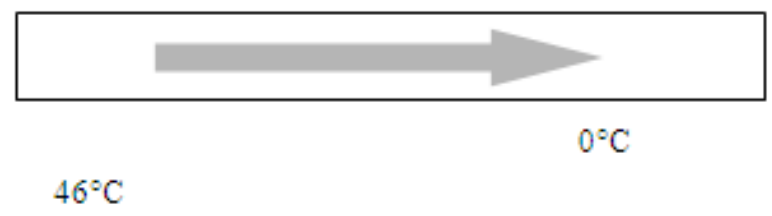

Source: Ar. Dr. Shakeel Qureshi, Lahore.

Figure 1. Variation of temperature measured 1.2 meter above ground level in shade.

\subsubsection{Energy consumption in Lahore}

The major part of electricity is consumed in Lahore by the domestic sector. This is done to attain the comfort zone in the houses located in composite climate of Lahore.

Table 1. Energy consumption Statistics

\begin{tabular}{|c|c|}
\hline Sectors & Energy Consumed \\
\hline Domestic & $38 \%$ \\
\hline Industrial & $25 \%$ \\
\hline Agriculture & $10 \%$ \\
\hline Commercial & $6 \%$ \\
\hline Others & $21 \%$ \\
\hline
\end{tabular}

Source: WAPDA Electrical Engineering Department (The Pakistan Water and Power Development Authority)

The shortest day of the year i.e. December $22^{\text {nd }}$ were made. These calculations were subject to the orientations of the building. The following formula can be used for radiation calculations.

$$
\operatorname{Cos}(\theta)=\operatorname{Cos}(\mathrm{A}) \quad \mathrm{x} \quad \operatorname{Cos}(\mathrm{WSA})
$$

Where,

$$
\begin{aligned}
\mathrm{A} & =\text { Angle of Altitude* } \\
\text { WSA } & =\text { Wall Solar Azimuth } \\
& \text { ** }
\end{aligned}
$$

The angular positions for different degrees of radiation can be given as below:

For maximum radiation:

$$
A=0^{\circ} \quad \text { (For North }
$$

Orientation)

WSA $=0^{\circ} \quad$ (For North Orientation)

And for minimum radiation:

$$
\mathrm{A}=90^{\circ} \quad(\text { For }
$$

East

Orientation)

$\mathrm{WSA}=90^{\circ} \quad$ (For East Orientation)

To measure the angle of the sun in its motion across the sky, we need to take its altitude and azimuth reading. (Lee Jin You, Roger et-al, 2009) ${ }^{2}$.

\section{Significance of the Eco House}

To cope with the severe variation of weather and temperature of Lahore city, and for the better being, the comfort zone is attained by consuming electricity. As the house is a place where the day starts, and also culminates, thus the domestic buildings end up consuming maximum electricity. Pakistan cannot afford that since she is already under the severe burden of depleting energy resources along with rising demand of electric power.

*Altitude is the angular distance above the horizon measured perpendicularly to the horizon. It has a maximum value of $90^{\circ}$ at the zenith, which is the point overhead.

**Azimuth the angular distance measured along the horizon in a clockwise direction. The number of degrees along the horizon corresponds to the compass direction. Azimuth starts from exactly north, at 0 degrees, and increases clockwise 
Therefore, to conserve energy Eco Houses are a necessity. Moreover, as the sun radiations are a major cause of skin diseases and environmentally harmful, hence Eco Houses is advisable solution that the architects should be considering while designing any accommodation. (Roaf. S 2009)

\subsection{Descriptions of the existing non Eco- House}

The house shown in figure one is located in Pakistan's eastern city of Lahore. The city is situated at the latitude of $32^{\circ}$. Since the seasonal difference of weather conditions in Lahore are at extreme. The placement of the house P-120 is East-West it is a longitudinal orientation, wherein the sleeping and resting functional areas are situated in the eastern zone. There is an adjacent playground location, which has no shading device this result in direct penetration of the sunlight in this house. In the figure two, the yellow arrows represent the path of the sun. The house is flanked by two roads, this result in the increase of heat penetration. The house is situation on a corner site resulting in facing maximum sun throughout the day, there is no prevention against heating except consumption of maximum electricity for the attainment of internal comfortable temperature. The house shown in figure two; facing the sun though out the day; has the fenestration of almost $10 \mathrm{~m}^{2}$ on every elevation. The front elevation faces west; where there is a location of living room; this location faces the sun in the evening hour. As a result the occupants use further more electric power to attain appropriate comfort zone.

The radiation is maximum in the evening. It is the sitting space where all the heat is penetrated through glazing, which is almost $10 \mathrm{~m}^{2}$. The radiation penetration calculated here is almost $8,500 \mathrm{~W} / \mathrm{m}^{2}$, at $0600 \mathrm{p} . \mathrm{m}$. when the rays of the sun are parallel with the windows. Again in the evening maximum air-conditioning is required here, hence a lot of electricity is used to provide air-conditioning. Whereas in the morning till 1200 p.m. the radiation is constant, when this façade faces no sun in the morning.

Whereas the West elevation facing the maximum sun in the evening. On the other hand; the northern elevation only sees the sun in the morning and in the evening. Compared to the other elevations the Sun is minimum on northern side on $22^{\text {nd }}$ June.

On 21 June the northern façade faces maximum sun since the angle is very high, this elevation will face the sun for two hours in morning and two hours in evening. Total radiation on $21^{\text {st }}$ June is $51900 \mathrm{~W} / \mathrm{m}^{2}$. The measurement of fenestration is $13 \mathrm{~m}^{2}$ as seen in the second column; the maximum radiation on this day is $5530 \mathrm{~W} / \mathrm{m}^{2}$.

East elevation faces sun in the morning times on $22^{\text {nd }}$ December, the radiation penetrates in the morning times, in this house no P-120, here in eastern side, bed rooms are located, and electricity is consumed to in the morning time at $0600 \mathrm{am}$, to lower the temperature of this room, when the radiation of $8641 \mathrm{~W} / \mathrm{m}^{2}$. After $1200 \mathrm{pm}$ the radiation is constant since, after $1200 \mathrm{pm}$ this elevation faces no sun.

The radiation is maximum $10315 \mathrm{~W} / \mathrm{m}^{2}$ at the mid day and minimum $6218 \mathrm{~W} / \mathrm{m}^{2}$ at the starting and culminating of the day. The total radiation is $112853 \mathrm{~W} / \mathrm{m}^{2}$. Wall azimuth is $180^{\circ}$ on $22^{\text {nd }}$ December on the southern façade. The measurement of fenestration is $13 \mathrm{~m}^{2}$ on this elevation.

On 22nd December the sun is very low; so much that the sun never sees this elevation at all on this day; the measurement of the fenestration is almost $13 \mathrm{~m}^{2}$. Since the wall azimuth is $0^{\circ}$, the total radiation through this elevation is 44157 watts per meter square.

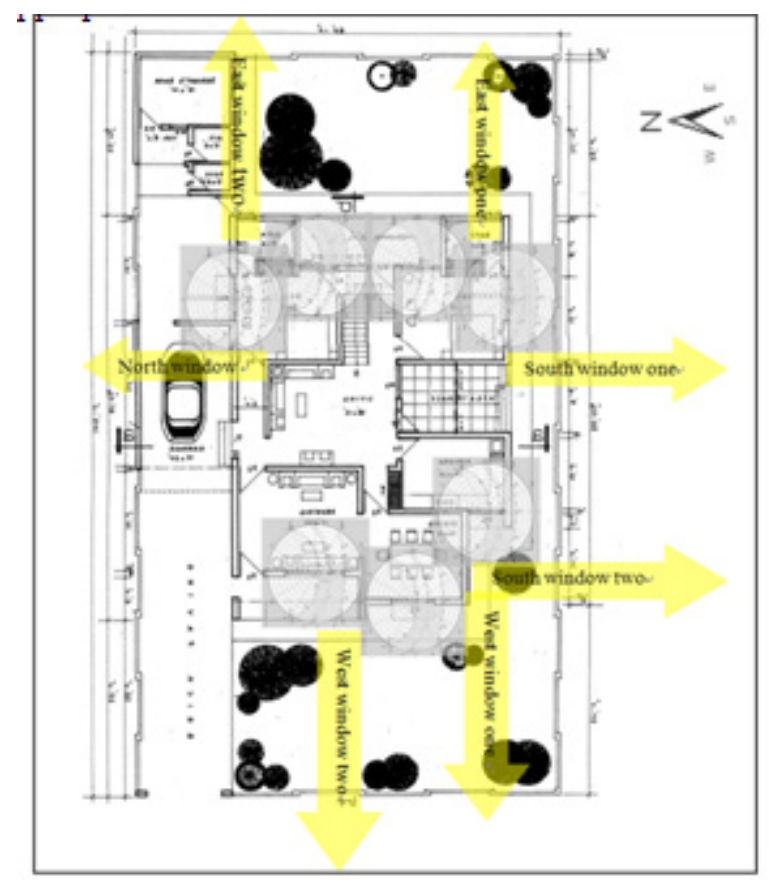

Figure 2. Sun chart on the plan of P-120 House with orientation. Plan of house P-120, UET Staff colony Lahore, source (Planning and Work department UET Lahore)

This house on a small plot of $209 \mathrm{~m}^{2}$ has an accommodation of four bedrooms with all required facilities and yet has an area of $167 \mathrm{~m}^{2}$ (i.e. $80 \%$ of plot area) being green and landscaped as shown in figure 2 and $3 .{ }^{1}$ In the extreme weather conditions, it remains comfortable during summers where temperature rises to $46^{\circ} \mathrm{C}$ without any air-conditioner; and during winter's when the temperature drops to $0^{\circ} \mathrm{C}$, it remain under comfort zone without any heater. Here economy is achieved in construction cost as well as in maintenance cost

The South elevation the radiation is maximum in the mid day i.e. at 1200 p.m. It goes up to $4500 \mathrm{w} / \mathrm{m}^{2}$. The glazing size on south wall is almost $13 \mathrm{~m}^{2}$ at 0600 p.m. as well as 0600a.m. The radiation at those times is minimum 3396 watt per meter-square. The constant is added as shown in the formula given in heading 2.1 .

\section{Design of the Eco House}

This Eco House is designed in a community context for up to six inhabitants. It aims to minimize the maintenance and use of the earth's resources such as, water, fossil fuel energy, 
and materials; for the entire life cycle. Based upon this less maintenance strategy it adopts slow building principles. Moreover, this house is aimed to be full of delight.

It is supposed to be extremely robust and is meant to last ideally till the end of the century. It provides solutions for increasingly extreme weather events along with the rising energy prices.

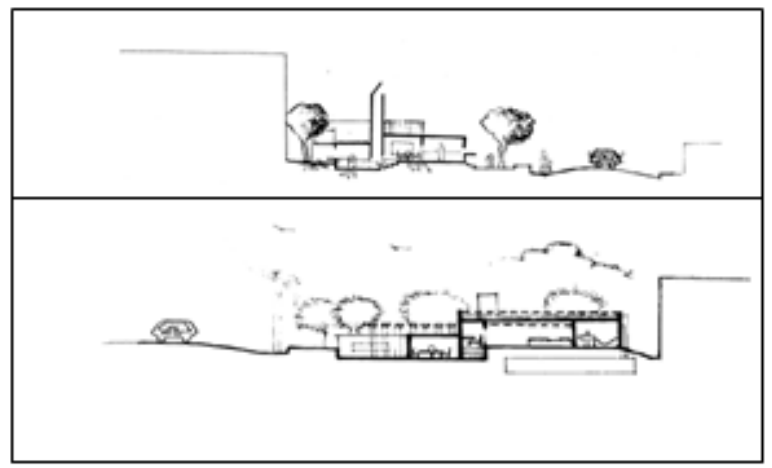

Figure 3. Longitudinal sections A and B (author)

These Eco House design section presented in Figure 3 above (plan Figure 5) shows the level changes. The wind chimney designed to maximize the ventilation, so that the energy performance can be improved in the monsoon period. The entrance level is elevated five feet high, to prevent rain water accumulation. The children room is depressed five feet under the ground level to ensure tenderness; the roof of this children room is designed to be green, which is watered by the rain water collected at the sky-therm system 2 located on the master bed room. The roof of the master bed room, act as a dam to collect rain water, which is stored and recycled in the storage and recycling plant system, located underground, shown in hatched line. The eastern portion of the house; kitchen is designed. The lounge is facing north western orientation; this location is already under the shade of the pre-existing building. In the above sections the existing trees on the site were integral part of the design solution, trees were incorporated in the design to reduce pollution, and to propose utmost green and ecological solution.

\subsection{Comparison of houses P-120 and Echo House on ECOTECT}

The above Figure 4 is constructed on ECOTECT software; there is massing and energy stimulation for the Eco House proposal. The shading for the sun is shown for a high angle for the hottest day using the tools, and the shading angles are studied. Initially the plan is traced and heights are allotted, then the fenestrations are sculpted in the Ecotect model, and after that the materials are assigned through tools of the software.

The Figures $4 \mathrm{a}$ as well as $4 \mathrm{~b}$ both show the vertical curved

2 The roof pond idea was originated by Harold Hay and first embodied in the Skytherm House at Atascadero, CA. line, this line shows the hour clock according to the sun, and the vertical straight lines show the hours per day. Smaller latitudinal line shows the sun path in winter; whereas loner latitudinal line shows the path in summer.

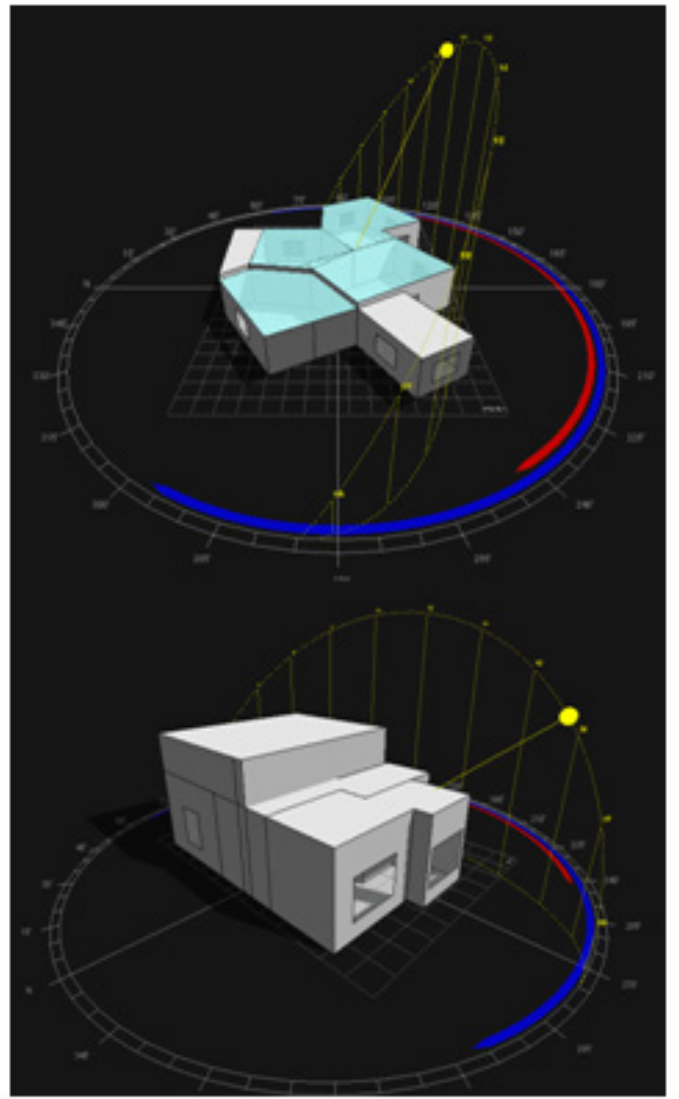

Figure 4. ECOTECT Analysis of the sun effects on the Echo House left 4a and $\mathrm{P}-120$ right $4 \mathrm{~b}$

In the Figure $4 \mathrm{~b}$ the model for the house $\mathrm{P}-120$, is constructed on Ecotect software. It is showing the sun diagram that how the sun radiations enter the building in a harsh manner. The yellow curved line shows the direction of movement for the sun. The huge fenestration invites the sun in summer, and the occupants are bound to use excessive air-conditioning, to achieve a liveable condition inside the house. In figure $3 \mathrm{~b}$, on the western façade, it is clear that how the sun light penetrates through the whole depth of the house. The blue curve shows the sun path in summer and the red line shows the path in winter.

Sun path diagram is shown in figure five, where sun rays penetration has been studied throughout the day on every window. The windows are designed with special consideration of sun light penetration, where double skin is used, to prevent harsh sun from entering directly. It is also visible from this figure that the trees are present in a way to prevent the penetration of sun light directly inside. The bamboos are used to make the outer temporary skin for the building, made in summer and removed in winter to invite the sun which is desirable since its angle is low. 


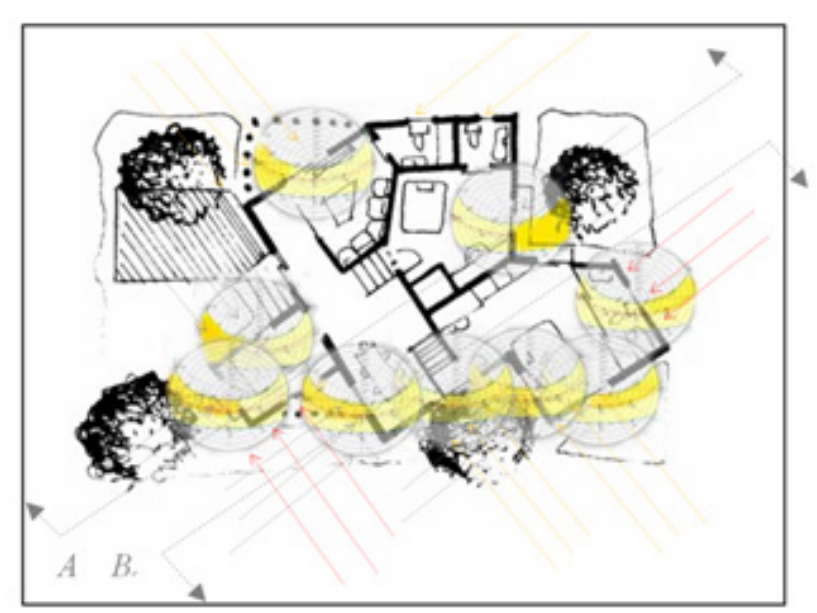

Figure 5. The sun path diagram on the eco house design.

\subsection{Comparison of houses P-120 and Echo House through radiation for $22^{\text {nd }}$ June}

Comparison of the house P-120 and the Eco House proposal sun radiation penetration through windows is shown below. The major difference in the radiation penetration on $22^{\text {nd }}$ June is visible.

Table 2. Total radiation in $\mathrm{W} / \mathrm{m}^{2}$ for house $\mathrm{P}-120$

\begin{tabular}{|c|c|}
\hline Orientation & Radiation \\
\hline East & 58985.36 \\
\hline South & 48870.08 \\
\hline West & 59044.17 \\
\hline North & 51900.59 \\
\hline & 218800.2 \\
\hline
\end{tabular}

Table 3. Total radiation in $\mathrm{W} / \mathrm{m}^{2}$ for Eco House proposal

\begin{tabular}{|l|l|}
\hline Orientation & Radiation \\
\hline East & 944.17 \\
\hline South & 944.17 \\
\hline West & 4822.33 \\
\hline North & 2031.51 \\
\hline & 8742.18 \\
\hline
\end{tabular}

In the above Table 2 there is an average for the radiation calculated, for the house P-120. The total radiation for four elevations on $22^{\text {nd }}$ June is $218800 \mathrm{w} / \mathrm{m}^{2}$, which is very high. On the other hand, as shown in table three the total radiation for the four elevations of the Eco House designed by the author, is $8742 \mathrm{w} / \mathrm{m}^{2}$ which is $70 \%$ lesser than $218800 \mathrm{~W} / \mathrm{m}^{2}$.

The energy performance, of both the houses was directly proportional to the radiation, the more the radiation penetrated; the more was the energy consumption, where as if the radiation penetration was reduced, this immensely effected the energy consumption, and reduced the energy use to minimum.

Hence, it is clear that the set target was achieved, which was to reduce energy consumption up to $70 \%$, it is evident that if radiation penetration was reduced, this results in extremely low air conditioning needs.

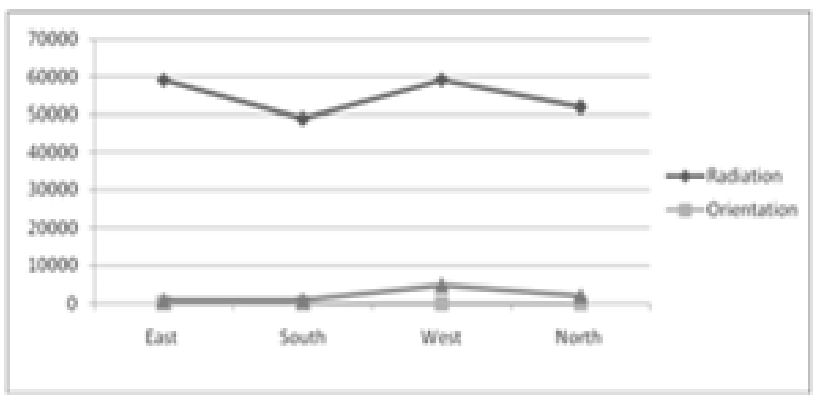

Figure 6. Comparison of Houses on $22^{\text {nd }}$ June

The Figure 6 represents the graph, where the vertical side represents the radiation, and the horizontal side presents orientation. The dark gray colour represents the reading for the present house at UET staff colony, P-120. Its reading falls between 50,000 to $60,000 \mathrm{~W} / \mathrm{m}^{2}$. On the other hand in lighter gray colour there is radiation penetration calculation for the Eco House proposal. The result falls within 5,000 $\mathrm{W} / \mathrm{m}^{2}$.

\section{Conclusion}

This paper deals with the issue of comfortable living, i.e. a living that can satisfy the emotional feelings of the occupants by two ways. Firstly, by the aesthetics that is the tangible aspects, and secondly, by the monetary compensation that is the economical energy consumption aspects of an affordable accommodation.

This paper revolved around the core theme of Eco House (ecological architecture), which is discussed here as a viable alternative of low carbon, environmental friendly, and healthy living. The beauty of this solution is its sustainability. Not only this solution provides low energy consumption for the present dwellers but also this is considered to be essential for preserving resources for the future generations.

Hence it can be concluded that a good low-carbon buildings will provide

- Appropriate indoor conditions

- Possibilities for adjustment

- Freedom to adapt

The Eco House proposal is designed with the help of modern state of the art software ECOTECT. This software provides a complete informative list about the latest products and appropriate building materials to be used in the building which the architects should select according to their choices. There is a complete wealth of options for graphic representation contained in this software along with the visual information.

The results are drawn for the two types of houses on the 
basis of comparisons of the calculations of radiation recorded; on June $22^{\text {nd }}$ the hottest and the longest day in the year; this provides substantial material to help analyze the findings based upon the facts.

Although there are certain limitations of the Eco-Houses, yet on the average it is the most suitable option that the architects of today should pay attention towards while designing the new houses. The concept will even further be explored in future studies by the author and the invitation is open to all the architecture students to discuss and debate this subject.

\section{Acknowledgements}

We are very grateful following for their appropriate and constructive suggestions to improve research. I pay my thanks to my supervisor Dr. M. Yousuf Awan. And I recognize the efforts of Dr. Shakeel Qureshi; towards completion of this dissertation. Furthermore, I am grateful to and Dr. Anees Siddique for his generous support and assistance.

\section{REFERENCES}

[1] Raof. S, Eco house 2 a design guide ,(2003)Architectural Press, Oxford, pp 55

[2] Fuller. M, (1993), Environmental Control Systems Heating cooling lighting, Mc-Graw Hill Inc, Singapore, pp 76

[3] IEA (n.d). Energy efficiency requirements in building codes, Energy efficiency policies for new buildings, IEA information paper. retrieved on June 82009 from http:/www.iea.org/Textbase/publications/free_new_ Desc.asp?PUBS ID $=2084$

[4] Q. Shakeel House, (1997) Architecture and interior A+I Magazine, Archi Times, Karachi,

[5] Roaf. S Adaptive Standards for Thermal Comfort in Buildings, (2009) Heriot Watt University, International Seminar, Saint John International University, Sustainability for Building Renovation and Restoration, Torino, Italy. 